\title{
Examining the Historical Developments and Contemporary Relevance of the Longitudinal-Experimental Design of the Cambridge-Somerville Youth Study: Utility for Research on Intergenerational Transmission of Offending
}

\author{
Steven N. Zane $^{1} \cdot$ Brandon C. Welsh ${ }^{1,2}$ - Gregory M. Zimmerman ${ }^{1}$
}

Received: 13 March 2016/ Accepted: 20 July 2016/Published online: 29 July 2016

(C) Springer International Publishing 2016

\begin{abstract}
Founded in 1939, the Cambridge-Somerville Youth Study represents the earliest longitudinal-experimental study in developmental crime prevention, combining the aims of understanding how the developmental process is related to future offending (i.e., longitudinal focus) as well as attempting to prevent offending through an experimental intervention during early adolescence. This article examines the historical context in which this novel design arose and provides a review of studies performed by Joan McCord based on her age- 45 follow up of the study. The study made possible decades of research on developmental risk factors for delinquency and criminal offending. A central question that arises from McCord's body of research is how these risk factors are transmitted from parents to children. This article reviews extant research on the transmission of intergenerational offending, and discusses the potential of the Cambridge-Somerville Youth Study to contribute to this literature. Specifically, the prospective longitudinal design makes it possible to include the children of the study participants and investigate the intergenerational transmission of offending, while the longitudinal-experimental design allows for the investigation of the transmission of treatment
\end{abstract}

Brandon C. Welsh

b.welsh@northeastern.edu

Steven N. Zane

s.zane@northeastern.edu

Gregory M. Zimmerman

g.zimmerman@northeastern.edu

1 School of Criminology and Criminal Justice, Northeastern University, Churchill Hall, 360 Huntington Avenue, Boston, MA 02115, USA

2 Netherlands Institute for the Study of Crime and Law Enforcement, Amsterdam, The Netherlands effects. This potential research stands as a testament to the study's design and vision.

Keywords Developmental crime prevention . Developmental risk factors - Randomized experiment . Prospective longitudinal survey · Intergenerational transmission of offending

\section{Introduction}

Developmental crime prevention refers to interventions designed to prevent the development of criminal potential in individuals (Tremblay and Craig 1995). It can be contrasted with situational crime prevention-interventions designed to prevent the occurrence of crimes by reducing opportunities and increasing the risk and difficulty of offending (Smith and Clarke 2012)—and community prevention—interventions designed to change the social conditions and institutions that influence offending in residential communities (Hope 1995). Developmental crime prevention efforts largely target risk and protective factors discovered in studies of adolescent development (e.g., Deković 1999), with a special emphasis on the importance of parenting style, parental conflict, and childparent bonding (e.g., Galambos et al. 2003; Steinberg 2001). One of the earliest examples of a developmental crime prevention program is the Cambridge-Somerville Youth Study, a longitudinal-experimental intervention established in 1939. To date, few longitudinal-experimental studies in developmental crime prevention, or criminology more generally, have been attempted.

The term "longitudinal-experimental" generally refers to designs that include data collection at several points both before and after the experimental intervention (Farrington 2006). A chief benefit of the longitudinal-experimental 
design is economy, since the same cohort can be used to evaluate program impact-made possible by the experimental intervention-and investigate questions of causal mechanisms related to offending over the life course-made possible by the prospective longitudinal survey. In the present context, this means that when an intervention is aimed at early developmental stages, a large amount of information pertaining to the adolescent period can be collected as part of the intervention, allowing for future research to assess the efficacy of the intervention as well as study the development of offending from adolescence onward.

Longitudinal and experimental studies have "complementary strengths and weaknesses, and a combined longitudinal-experimental study could build on the strengths of both" (Farrington 2013, p. 493). For one, longitudinal-experimental studies are less risky than ordinary randomized experiments. If the experiment cannot be carried out successfully, or if there are major threats to internal validity, then the longitudinal aspect of the study is still valuable (as well as relatively unaffected by the failed experiment). Furthermore, while experimental designs are the best method for testing between-individual differences, longitudinal designs are the best method of testing within-individual change. As such, a longitudinal-experimental design is able to "compare the impact of variation with the impact of change" and study within- and between-individual variation simultaneously and interactively (Farrington 2013, p. 493). This also means that a longitudinal-experimental study is able to address unique questions, such as the long-term effects of an intervention begun in childhood or adolescence. The most well-known longitudinal-experimental studies in developmental prevention are the Cambridge-Somerville Youth Study (McCord 1978), the Montreal LongitudinalExperimental Study (Vitaro et al. 2013), the Nurse-Family Partnership (Eckenrode et al. 2010), and the Perry Preschool Project (Schweinhart et al. 2005). Of these, the CambridgeSomerville Youth Study is the earliest by several decades.

The main aims of this article are to examine the context in which this first longitudinal-experimental study arose and to explore the many research possibilities it has created for understanding the relationship between adolescent development and offending. Of special interest is the potential contribution it holds for investigating intergenerational transmission of offending. We begin with an overview of the historical context of the study.

\section{Historical Context of the Cambridge-Somerville Youth Study}

The Cambridge-Somerville Youth Study was developed in the 1930s by Dr. Richard Clarke Cabot, a professor of medicine and social ethics at Harvard University. Although his major contributions were to medical diagnosis and the etiology of heart disease, Cabot also made various contributions to social work, such as introducing social services to Massachusetts General Hospital and, in 1931, becoming president of the National Conference on Social Work (see Cabot 1934). By the early 1930s, questions of adolescent development and the origins of juvenile delinquency had apparently begun to take shape in Cabot's mind.

Cabot appeared convinced of the need for research on intervening in adolescent development for at-risk youth. Likely due to his medical background, Cabot was insistent that a rigorous scientific design be used to evaluate such social interventions. Otherwise, Cabot lamented: we are "forced to base our opinions of the value of any given piece of social work largely on the charter, experience, and expertness of those in charge of it" (Cabot 1931, pp. 15-16). Cabot looked forward to a day when controlled experiments, comparing treatment and control groups, would be used to evaluate social programs (Cabot 1931).

Within the next few years, Cabot himself would design such a social program. To do this, Cabot employed a highly rigorous matched-randomized controlled experimental design. Based on a clinical interpretation of more than 100 variables, including a teacher rating of whether the subjects were "average" or "difficult," a group of 650 boys (aged 5-13 years; median $=10.5$ ) from Cambridge and Somerville schools were placed into 325 matched pairs (Powers and Witmer 1951). One member of each pair was chosen at random (on a coin toss) to be in the treatment group. The program officially started in 1939. Due to resource shortages caused by the United States' entrance into World War II in 1941, the study was scaled back to 253 matched-pairs and lasted for 5 years. As others have noted, Cabot's design represents the first randomized controlled experiment in developmental crime prevention and criminology more generally (Weisburd and Petrosino 2004; see also Farrington 2013; Farrington and Welsh 2006), as well as one of the earliest uses of random allocation to study a social intervention (see Forsetlund et al. 2007). ${ }^{1}$

In short, Cabot's treatment philosophy itself was one of character development through positive role models (deQ. Cabot 1940). The treatment group received individual counseling and home visits. Counselors talked to the boys, took them on trips and to recreational activities, tutored them in reading and math, encouraged them to participate in the YMCA and in summer camps, and gave advice and general support to the boys' families. While each counselor was "left largely to his own resources" in the treatment of each boy, the "essence of the relationship between the boy and his counselor was personal intimacy

\footnotetext{
${ }^{1}$ The authors identified only nine studies prior to 1949 that used random allocation to study social or educational interventions.
} 
and friendship" (Powers 1949, p. 81). This treatment approach appeared to reflect Cabot's own personal views about the roots of delinquency in the lack of positive attachment to role models during adolescent development, something that Cabot sought to test experimentally. As McCord (1992, p. 198) later put it, "The CambridgeSomerville Youth Study grafted scientific methods onto a social action program."

\section{Criminology's First Longitudinal-Experimental Study}

McCord (1978) reported on the results of the 30-year follow-up (mean age $=45$ years) of the delinquency prevention experiment. Findings indicated that the program produced harmful effects. Her research was comprehensive, investigating and detecting iatrogenic effects for a wide range of important life-course outcomes, including criminal offending, physical and mental health, family stability, employment, and alcohol abuse. To compare outcomes across a common metric, McCord (1978) grouped subjects by whether or not they experienced any "undesirable outcomes," which included FBI index crimes (all of which were felonies), treated alcoholism, serious mental illness, and death. The results indicated that $42 \%$ of treatment group participants experienced undesirable outcomes compared to $32 \%$ of controls, a statistically significant iatrogenic effect $(p=.02)$. Due to its longitudinal-experimental design, however, the utility of the Cambridge-Somerville Youth Study was not limited to these program findings.

Although evaluating the prevention program "to test Cabot's belief about how a child could be steered away from delinquency" was the primary goal of McCord's early research, the evaluation was also designed to "learn about the development of delinquent youngsters," including risk and protective factors during adolescence (McCord 1992, p. 198). Cabot instructed counselors to keep detailed records of all encounters with the boys and their families. As P. S. deQ. Cabot ${ }^{2}$ suggested at the program's inception, an "outstanding characteristic" of the program plan was the combination of research and casework, such that "treatment and research objectives are closely intertwined" (deQ. Cabot 1940, pp. 143-150). Richard Clarke Cabot made clear that "other subsidiary researches may be carried out, such as, the causes of delinquency, longitudinal studies of personality development, the interrelationship of physical, social, mental and emotional factors and antisocial behavior, the validation of techniques of selection, of

\footnotetext{
${ }^{2}$ Richard Clarke Cabot passed away in 1939 and a relative, P. S. deQ. Cabot, took over as the study director (deQ. Cabot 1940).
}

multivariate matching procedures, or predictions of delinquency, as well as an evaluation of case records" (deQ. Cabot 1940, p. 143).

At the time, it was actually considered "unusual for one to carry on research with boys with whom one is at the same time attempting treatment" (Powers 1949, p. 83). From its beginnings, then, the Cambridge-Somerville Youth Study was envisioned as a longitudinal-experimental study, which created a unique opportunity to collect data through direct observation (by those delivering the treatment) over a long period of time (McCord 1992, pp. 203-204). As noted by McCord,

Dr. Cabot had been particularly interested in having documentation regarding the processes of family life and how these would be affected by the program. Therefore, the records contained detailed reports of what had transpired in the home. The records included almost verbatim reports of conversations as well as observations of interactions in the family (1999b, p. 243).

McCord coded these case records in 1957, producing a wealth of information on the boys and their families based on direct observations from 1939 to 1945-formative years (i.e., early adolescence) for the study boys. Importantly, such observations were only possible through the treatment aspect of the program (McCord and McCord 1959). Early on, McCord and McCord (1959, pp. 62-63) observed that "the legacy left to social science by the Cambridge-Somerville Youth Study is invaluable because, in the very nature of the experiment, retrospective biases were eliminated. Moreover, extensive observations by psychologists, social workers, and psychiatrists form a massive source of evidence." Had this information not been collected, conducting the prospective longitudinal survey part of the design would have been much more challenging and the study "would not have become so famous" (Farrington 2006, p. 130).

\section{Review of Findings on Family Risk Factors During Adolescence}

Family risk factors present one of the most important targets for developmental intervention (Steinberg 1987), and Joan McCord's age-45 follow-up of the Cambridge-Somerville Youth Study seemed largely motivated by her ongoing interest in the importance of the family for adolescent development (see Sayre-McCord 2007). For McCord, family socialization practices were essential to understanding antisocial behavior that developed during adolescence and persisted into adulthood. In part, this may have been due to her background in philosophy. She was fond of quoting Aristotle, who suggested that "[w]hether we form habits of one kind or of another from our very youth... makes a very 
great difference, or rather all the difference" (McCord 1993a, p. 321; quoting Nichomachean Ethics Book II, chap. $1)$.

In addition to her preoccupation with the role of the family in influencing adolescent development (as well as later adult behavior), McCord was acutely interested in causal mechanisms as well as in an honest recognition of the difficulty of establishing causality in social science research. She held that "longitudinal research has involved a deep commitment, a commitment that has seemed justified by the promise of answers to profound questions" (McCord 1994a, p. 177). This commitment prompted her to undertake a follow-up of the study participants in adulthood (median age $=45$ ). Finding an impressive $98 \%$ of the men $(\mathrm{N}=494: \mathrm{T}=248$, $\mathrm{C}=246$ ), McCord collected a substantial amount of data on program outcomes, including offending, alcoholism, mental health, and death (see McCord 2003). McCord also sent out questionnaires and conducted interviews, gathering self-report data from 347 participants ( $48 \mathrm{had}$ died at the time of the age-45 follow-up).

Using the follow-up data, McCord engaged in a prolific program of research on the relationship between family processes and deviance. Shortly after conducting the age45 follow-up, McCord (1979) reported that a series of family variables were significantly related to future offending for the treatment group boys: parental supervision, parental conflict, parental aggressiveness, mother's self-confidence, mother's affection, and father's deviance (criminality and alcoholism). In looking at patterns of deviance from juvenile offending to adult criminal offending in another early study, McCord (1980) found that parental rejection, parental conflict, and parental criminality were consistently and strongly related to juvenile delinquency. In addition to deviance during adolescence, McCord (1979, p. 1485) reported that "parental behavior does have an important impact on subsequent behavior: predictions of adult criminality based on knowledge of home atmosphere were not only markedly more accurate than chance-they were also more accurate than predictions based on the individuals' juvenile criminal records." One of the most consistent of these family risk factors was paternal criminality.

\section{Parental Transmission of Offending}

McCord (1991b) found that criminal fathers were significantly more likely to have criminal sons (45\%) than were noncriminal fathers $(28 \%)$. Similarly, criminal sons were significantly more likely than noncriminal sons to have criminal fathers ( $32 \%$ of criminal sons compared to only $18 \%$ of noncriminal sons had criminal fathers). Crime appeared to run in families, and McCord was motivated to discover why.
For example, McCord (1983) examined the relationship between father's and son's deviance in the context of overall family treatment by separating boys into four groups based on parental treatment directly observed during the adolescent period: neglected, abused, rejected, and loved. Paternal alcoholism and criminality were significantly related to the "rejected" group, but not with child abuse. For boys with deviant fathers, maternal affection also appeared to be a strong protective factor during adolescent development and was significantly associated with fewer future crimes. Similarly, McCord (1986, p. 352) found that "criminogenic families tend to be located in a three-dimensional space that can be characterized as one in which deviant, aggressive parents show little respect for other members of the family; mothers are insecure, inconsistent, and not affectionate; and no one provides supervision or attempts to direct the children's behavior." In other words, a perfect storm of family risk factors appeared responsible for the transmission of antisocial behavior from fathers to sons during adolescence.

McCord reached the conclusion that offending and alcoholism were not directly transmitted from parents to children via social learning or biological inheritance, but rather that parenting practices and other family risk factors provided the causal pathway through which parental deviance was transmitted to children (McCord 1986, p. 355). This conclusion was based on a host of studies showing a strong association between father's criminality and parental conflict and aggressiveness. In a study on the transmission of alcoholism, for example, McCord (1988b) found that while paternal alcoholism was the strongest predictor of a son's alcoholism, maternal behavior toward the alcoholic father was also important. McCord (1999a) also found that both alcoholic and criminal men were significantly more likely to be aggressive fathers and to be married to incompetent mothers. This provided further evidence that "alcoholism and crime tend to run in families at least partially because alcoholic and criminal parents tend to provide poor socializing environments" (McCord 1999a, p. 114).

In other research, McCord (1990a) rated families according to child rearing practices. Sons raised by criminal fathers were less likely to be reared in "good" families while sons raised by noncriminal fathers were more likely to be exposed to "good" parenting practices. Of the "worst" 38 families, $39 \%$ of fathers had been convicted of serious, index crimes; of the "best" 61 families, only $11 \%$ of fathers had been convicted. McCord (1990b) also found that the significant relationship between father and son criminality only held among intact families-there was no relationship where criminal fathers were absent. Consistent with her other findings, McCord (1990b, p. 132) concluded that parental behavior "has a stronger impact than family structure." 


\section{Causal Complexity of Transmission Mechanisms}

In her later work, McCord became interested in investigating the causal complexity of the relationship between father and son criminality. In large part, this was done through exploring interactions with other family risk factors that might condition the influence of parental criminality. McCord (1991b) found that criminal fathers were more likely to be highly aggressive and punitive, more likely to be alcoholic, and more likely to be absent from the home or to be married to aggressive mothers. Parental conflict and parental aggressiveness were the only risk factors related to future criminality for all sons (i.e., via both criminal and noncriminal fathers).

McCord (1988a) also found that exposure to general aggressiveness was more predictive of future criminality than punitive training in otherwise nonaggressive families. McCord (1991a) examined the relationship between paternal criminality and physical punishment, finding that criminal fathers were more likely to use physical punishment (73\%) than were noncriminal fathers (48\%). Findings indicated that having a criminal father and being subjected to physical punishment (compared to a criminal father that did not use physical punishment) was associated with criminality in sons (63\% compared to $33 \%$ ). This and other similar findings suggest a complex picture where parental criminality is associated with many other risk factors that produce antisocial behavior in children and adolescents. McCord (1994b, p. 242) suggested that this complexity creates challenges in identifying singular causal mechanisms, observing, for example, that while parental conflict was often posited as a social cause of children's antisocial behavior, "if parental conflict were itself caused by children's misbehavior, then parental conflict might be no more than a perturbation in the linkage of aggression between generations."

Another example of this complexity involves neighborhoods. In the same study, McCord (1991b) examined how neighborhoods might influence the transmission of offending, finding that "unstable neighborhoods appeared to have a criminogenic effect only on sons who had a criminogenic heritage" (p. 223). For sons of noncriminal fathers, $34 \%$ of criminal sons came from the worst neighborhoods compared to $31 \%$ of noncriminal sons-not a significant difference. But, for sons of criminal fathers, $45 \%$ of criminal sons came from the worst neighborhoods compared to only $15 \%$ of noncriminal sons. McCord (1991b) suggested that noncriminal sons of criminal fathers did not tend to come from the worst neighborhoods because they likely had important protective factors in their communities to prevent them from following in their fathers' footsteps. Importantly, these protective influences included maternal traits such as affection, self-confidence, supervision, and nonpunitive discipline. In a later study of neighborhoods, she likewise suggested that "[e]ffects of neighborhoods seem to be mediated by family socialization practices, but whether or not similar socialization practices have similar effects in different types of neighborhoods is not yet known" (McCord 1993a, p. 322). More recent research has continued to explore the relationship between family and neighborhood, and has generally found that family factors do partially condition the effect of neighborhood characteristics on various outcomes (see, e.g., Deng et al. 2006; Fan and Chen 2012; Mahatmya and Lohman 2012; Schofield et al. 2012).

A final important mechanism that McCord explored was biological. The question of whether parental transmission of antisocial behavior is due to "innate disposition" or "contagion from social environment" goes back centuries, yet remains a mystery (McCord 1991b, p. 226). McCord (1994b, p. 244) investigated the "genetic" and "social" hypotheses with two generations (fathers and sons) in an attempt to "disentangle the web linking generations in terms of criminality." By looking at parental criminality, early childhood behavior problems, parental conflict, behavior problems during adolescence, and adult sons' criminality, McCord (1994b) concluded that the criminogenic effects of paternal criminality appeared largely due to exposure to marital discord rather than a direct (or genetic) transmission that was observable in early childhood problems. Similarly, McCord (1999b) concluded that while biological and social mechanisms were likely both part of the causal explanation (see also DeLisi et al. 2010), social conditions appeared more important. McCord (1994b, p. 248) remained careful not to dismiss completely the genetic explanation, however:

It would be a mistake... to conclude that this shows no genetic contribution to misbehavior. Rather, whatever genetic makeup has been passed from father to son ought to be viewed as providing susceptibilities or potentialities which require social conditioning for their expression in terms of crime.

In sum, McCord was well aware that the collinearity of various risk factors presents a serious challenge to understanding the causal mechanisms underlying the relationship between parent and adolescent antisocial behavior (see McCord 1993b). Only a carefully constructed prospective longitudinal design is capable of exploring these complex issues of causal ordering - and even then, may be unable to capture fully the underlying mechanisms at play.

\section{Intergenerational Transmission of Offending}

One method for investigating these complex causal relationships is to employ an intergenerational design. Just as prospective longitudinal designs are necessary to assess the effect of risk factors within individuals over time 
(Farrington 2013), intergenerational designs are necessary to examine the causal mechanisms underlying the observed continuities in offending across generations. For instance, several generations are necessary to test whether crime truly "runs in families" or is limited to the parent-child relationship. Beyond offending, intergenerational designs have recently been employed to a host of other adverse behaviors that appear to run in families, including early childhood conduct problems (Raudino et al. 2013), depression (Hammen et al. 2011), age of sexual onset (Johnson and Tyler 2007), adolescent self-criticism (Bleys et al. 2016), and child abuse and neglect (Widom et al. 2015).

Thornberry (2009) distinguishes longitudinal and intergenerational designs based on whether a third generation (G3) is included in the study design. The third generation is important because it allows for a comparison between a parent's antisocial behavior during adolescence (G2) and an offspring's antisocial behavior during adolescence (G3). This can be contrasted to a longitudinal design in which only the parent's adult behavior (G1) is compared to an offspring's adolescent behavior (G2). With a longitudinal design, it is challenging to separate various causal mechanisms because the offspring's adolescent behavior may be directly influenced by the parent's adult behavior. But an offspring's adolescent behavior should not be affected (directly) by the adolescent behavior of the parent (to which the offspring is not exposed). As Thornberry (2009, p. 300) observes of the intergenerational design, "The focal participants are the children in the third generation, and it is their antisocial behavior that we are attempting to explain" by reference to grandparent (G1) adult behavior, parent (G2) adolescent behavior, and parent (G2) adult behavior. This kind of investigation requires at least two generations of prospective data: G2 and G3. Figure 1 clarifies the differences between an intergenerational design and a traditional longitudinal design.

Cabot's vision for delinquency prevention focused on child development in the context of the family, and accordingly McCord's follow-up research largely examined questions of family risk and protective factors. As noted above, much of McCord's follow-up work on the Cambridge-Somerville Youth Study was motivated by the relationship between parental behavior (in adulthood; G1) and child behavior (G2) both in adolescence and adulthood. As McCord (2001, p. 223) put it, "Families contributed to criminality in at least three ways: by genetic transmission, through placement in physical and socioeconomic contexts, and by virtue of child-rearing practices." Intergenerational designs represent the next step for investigating the interplay of these complex causal mechanisms.

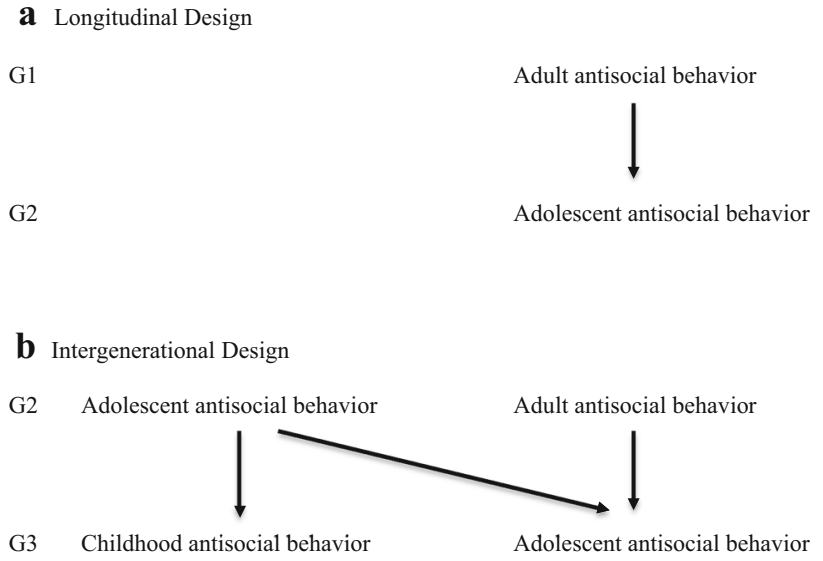

Fig. 1 Longitudinal design compared to intergenerational designSource: Adapted from Thornberry (2009, p. 301)

\section{Exploring Causal Mechanisms}

While McCord (2001) postulated three primary pathways for intergenerational transmission, Farrington (2011) identified at least six possible causal mechanisms: continuity in environmental risk factors, assortative (selective) mating, social learning, family risk factors, genetics, and official bias (see also Farrington et al. 2001).

\section{Continuity in Environmental Risk Factors}

According to this mechanism, transmission would not be direct but instead would be due to shared social-structural environment: "The mechanism is the lack of successful routes out of poverty for children of poor/offending families" (Williams and Godfrey 2015, p. 201). If the significant association between parent and child criminality is reduced (and confounding is therefore at play, at least in part) when community and structural issues are controlled, then continuity in exposure to environmental deprivation may explain intergenerational transmission of offending.

\section{Assortative Mating}

A second causal mechanism posits that criminal/delinquent/antisocial persons tend to become married to or partners with other criminal/delinquent/antisocial persons. This could be due to social homogamy-a shared social world (i.e., proximity) — or because they are attracted to similar personalities (i.e., phenotypic assortment). In either case, research shows that criminal persons are more likely to have criminal spouses compared to noncriminal persons (Farrington et al. 2001). 


\section{Social Learning}

A third causal mechanism is social learning. This is arguably the most direct causal mechanism since it posits that the association between parent and child's criminality is due to learning (including imitation) by the child. A strong association between persistence of parental offending and child offending would provide evidence for social learning or differential association, since the parent is the "social role model for the children" and more frequent offending provides "more opportunities to observe and imitate their parents' delinquent behavior and motivations" (Besemer and Farrington 2012, p. 121).

\section{Developmental Risk Factors}

In contrast to this direct transmission of offending, a fourth causal mechanism posits that transmission is mediated by developmental risk factors (Farrington 2011). Family risk factors-such as parental conflict, parental absence, lack of supervision, large families, and young parents-appear to be the more direct cause of antisocial behavior and criminal offending, and parental criminality just happens to be associated with these risk factors (Farrington et al. 2009). In other words, criminal parents tend to be bad parents, and bad parents are more likely to produce deviant children and adolescents. While McCord acknowledged that transmission mechanisms are not mutually exclusive and could all contribute to the association between parental and child's antisocial behavior, deviance, and criminality, her extensive research on two generations pointed to shared family risk factors as an important-and perhaps central-part of the explanation (see, e.g., McCord 1991a, b, 2001).

\section{Biological Transmission}

A fifth mechanism - and perhaps the most obvious explanation for intergenerational transmission of offending-is genetic transmission of traits that predispose a person toward a life of crime (Farrington 2011). McCord (1999c, p. 176) suggested that "some combination of environmental and genetic conditions most likely accounts for the transmission of violence within families." The best way to examine the contribution of heredity would be to study genetic twins raised by different parents in different environments, or to compare adopted children to genetic children. While such research has provided strong support for the role of biology in criminal and other antisocial behavior (Raine 2002, 2008), insufficient attention has been paid to the possibility of genetic transmission of risk factors related to criminal offending (see Bijleveld and Farrington 2009; but see van de Weijer 2014).
As Farrington et al. (1996, p. 47) have observed, the implication that intergenerational transmission may be due (in part) to genetic transmission, has likely halted progress on studying the intergenerational transmission of offending: "American criminologists were trained as sociologists and are concerned to avoid any suggestion that offending might be genetically transmitted." For example, one criminologist recently opined that "Biodeterminist claims are the most profound and potentially dangerous that scientists can make about human beings.... [and] should be subjected to the strictest levels of scientific skepticism, ethics, and scrutiny" (Males 2009). But as McCord (2001, p. 224) suggested, evidence indicates that "genetic determination takes place within epigenetic contexts" (see also Tremblay 2005) and without the implications of a pure biological determinism (see also Delisi et al. 2010). To date, no intergenerational studies have "attempted explicitly to address nature-nurture mechanisms by collecting genetic information or by investigating transmission for biological or non-biological children (or in twins). Such tests are important in disentangling biological from nonbiological explanations in the transmission of antisocial behavior" (Bijleveld and Farrington 2009, p. 79).

\section{Official Bias}

Lastly, a labeling perspective suggests that there is an official bias against "criminal" families. This bias results in more criminal arrests and convictions for the children of criminal parents-irrespective of whether the children actually commit more crime compared to children of noncriminal parents (Farrington 2011). Besemer et al. (2013) found some evidence of official bias by comparing official convictions to self-reported offending. Specifically, they found that parental convictions were more strongly associated with offspring convictions than with self-reported offending, and that certain "biasing variables" were significantly related to official convictions but not to selfreported offending.

As noted, these six causal mechanisms are not mutually exclusive. Ultimately, it would appear most likely that "the environmental context and the mechanisms for intergenerational transmission seem... to be inextricably bound together" (Williams and Godfrey 2015, p. 201), something McCord emphasized. Of the possible causal mechanisms, however, research consistently points to parental influence (i.e., direct exposure) as a central ingredient of intergenerational transmission, an important early finding-and one corroborated by McCord's decades of research on the Cambridge-Somerville Youth Study. Whether this association is more attributable to social learning or continuity of family risk factors is a question in need of further research. So far, few studies have been able to investigate these 
questions, and have not yet controlled for all possible influences ranging from genetics to social deprivation (Bijleveld and Farrington 2009).

\section{Extant Intergenerational Research}

McCord's research on the Cambridge-Somerville Youth Study did not venture beyond the father-son relationship, and few studies to date have examined more than two generations. Key studies that provide the requisite data for examining intergenerational transmission of offending across three generations-a true intergenerational design-include the Cambridge Study in Delinquent Development (West and Farrington 1977), the Rochester Youth Development Study (Thornberry et al. 2003), the Oregon Youth Study (Capaldi et al. 2003), the Criminal Career and Life Course Study (van de Rakt and Nieuwbeerta 2005), and the Transfive study (Bijleveld and Wijkman 2009). ${ }^{3}$ The longest running of these is the Cambridge Study in Delinquent Development, a study of 411 London boys born in working-class neighborhoods in 1953 and followed prospectively from age eight to 56 (Farrington et al. 2013). Between 2004 and 2007, the children (G3) of these men (G2) were interviewed-allowing for an investigation of intergenerational transmission (Farrington et al. 2015).

In the United States, two major prospective longitudinal studies have been used to investigate intergenerational transmission of offending. The Rochester Youth Development Study involves 1000 7th and 8th graders selected from public schools in Rochester, New York, in 1988 (Thornberry et al. 2003). Participants were followed from age 14 until age 36. In 1999, children of the participants were added and followed from age 2 through age 24 (Thornberry 2009). The Oregon Youth Study followed 206 male fourth grade students (age 10) in high-crime areas for approximately 28 years (up to ages 37-38). Children of participants have also been included-making this a threegeneration study - and have been followed through age nine (Capaldi et al. 2012).

The two other studies come from the Netherlands. The Criminal Career and Life Course Study involves a sample of 5656 individuals prosecuted in the Netherlands in 1977 (van de Rakt and Nieuwbeerta 2005). A subset of these men $(\mathrm{N}=3015)$ had children who were followed up $(\mathrm{N}=6921)$. Although not a prospective survey, a matched control group of non-convicted men $(\mathrm{N}=485)$ and their children $(\mathrm{N}=1066)$ was also included in the final sample. While this study has the disadvantage of not being

\footnotetext{
$\overline{3}$ This does not purport to be an exhaustive list, but includes multigenerational studies that have prompted research on intergenerational transmission of offending.
}

prospective by nature, it provides the largest sample for the study of intergenerational transmission. The Transfive study is a five-generation study using conviction data from 1870 to 2007 in the Netherlands (Bijleveld and Wijkman 2009). Transfive includes 198 high-risk boys who were registered in reformatory school between 1911 and 1914, their 367 parents, 627 children, and 1982 grandchildren. Like the other Dutch study, Transfive uses official convictions and did not collect self-reported data. There are also a few population studies which use official statistics for three or more generations, including a national study in Sweden (Frisell et al. 2011) and a single city study in the Netherlands (Junger et al. 2013).

Two major findings have emerged from early research on the intergenerational transmission of offending and other antisocial behaviors. First, three-generational studies have generally found similar evidence of transmission of offending and other antisocial behaviors when comparing G1-G2 as well as G2-G3 (but see Capaldi et al. 2012, finding no significant relationship between G2 and G3 antisocial behavior). Evidence of direct intergenerational transmission from G1 to G3, however, has not been substantiated, pointing toward parent-child transmission mechanisms.

Second, the transmission mechanisms with the greatest empirical support to date are family risk factors and social learning - the two mechanisms most related to direct exposure to a criminal or antisocial parent. The social learning hypothesis has received early support from several intergenerational studies. For one, direct exposure appears necessary for intergenerational transmission to occur (Thornberry et al. 2009; van de Weijer et al. 2014). van de Rakt et al. (2008) also found a significant association between number of convictions of criminal fathers and criminal offspring. In addition to frequency, van de Rakt et al. (2010) found an association between criminal trajectories for specific crimes of parents and children (see also Dong and Krohn 2015), suggesting a direct learning process. Besemer (2014) found that parental convictions before birth of their children were less related to offspring convictions, more consistent with social learning than a genetic explanation. ${ }^{4}$

Early research also supports McCord's findings and suggests the developmental risk factors explanation is a dominant mechanism of transmission. Thornberry (2005,

\footnotetext{
${ }^{4}$ However, parents who desisted at their child's birth also had significantly fewer risk factors for crime. This suggests an alternative interpretation: that parents who only offended before the birth of their children (and then desisted from crime) may be less serious criminals, either from the perspective of the criminal justice system (labeling) or in terms of a possible genetic predisposition toward delinquent behavior (Bijleveld and Wijkman 2009). It is important not to rule out all possible explanations for such findings.
} 
p. 183, emphasis added) describes the complexity of this process: "the onset of $\mathrm{G} 3$ childhood antisocial behavior and the formation of prosocial competencies are directly influenced by current $\mathrm{G} 2$ antisocial behavior patterns, G2 level of prosocial bonds and social capital, and G2 parenting style. The latter is likely to be the most powerful and proximate influence, mediating the effect of many of the prior variables." Smith and Farrington (2004) found that transmission of antisocial behavior appeared to be mediated by parenting practices such as poor parental supervision, which continued from fathers to sons. More recently, Farrington et al. (2015) found further evidence in support of a risk factor mechanism. Comparing over 20 shared risk factors between G2 and G3, they found that effect sizes correlated strongly (.80) and 11 risk factors were significant predictors of criminality for both generations.

\section{Limitations of Research on the Intergenerational Transmission of Offending}

Research to date on intergenerational transmission of offending has several limitations. Most notably, such research is incredibly difficult because it is both timeconsuming and expensive. In order to circumvent the difficulty of constructing intergenerational designs prospectively, some research has taken advantage of detailed official records to create an intergenerational design retrospectively (e.g., Bijleveld and Wijkman 2009; van de Weijer et al. 2014). This involves several drawbacks. For one, retrospective designs do not establish causal ordering as effectively as prospective designs (Farrington 2013). Official data is also less likely to include all relevant variables, in contrast to self-report data or even qualitative data (i.e., direct observation). Also, official convictions may underestimate the actual amount of crime and antisocial behavior to which children and adolescents are exposed, making it difficult to test different theories of intergenerational transmission (van de Weijer 2014). The Cambridge Study in Delinquent Development, Rochester Youth Development Study, and Oregon Youth Study each involve prospective designs and follow-up on G3 through adolescence, including qualitative or self-report data. Unlike the Dutch studies, however, these involve smaller, less generalizable samples. This points to a possible tradeoff between achieving a prospective, intergenerational design with detailed data collection (from direct observation or selfreports) versus having a larger and more representative sample.

Even for prospective designs, however, it can be difficult to establish causal ordering. More data collection is needed at all stages of development across generations in order to better test the different theories of intergenerational transmission, most of which are consistent with the mere observation that crime "runs in families" (Farrington et al. 2001). As Besemer (2014) observes,

The risk factors could be causing the offspring's offending separately from the parents' offending; the risk factors could be causing the parents' as well as the children's crime; or the parent's offending could be causing the risk factors and the risk factors could then cause the offspring offending. It was not possible to investigate the temporal sequence of risk factors and parent and offspring offending and, therefore, this study could not differentiate between Farrington's (2011) continuity versus mediation through risk factors mechanism.

In addition to timing, it can prove difficult to navigate among causal pathways based only on official or self-report data. For example, an association between parental offending after the birth of a child (but not before) and antisocial behavior in the child may appear to be evidence of a social learning pathway (i.e., direct) as opposed to a developmental risk factor (i.e., mediated) pathway. But, it would not establish direct causation, nor would it preclude the possibility of developmental risk factors also contributing to the transmission of offending. Direct, qualitative observation of families (such as G1 and G2 of the Cambridge-Somerville Youth Study) may present one possible response to this challenge.

Finally, no intergenerational design has yet to collect genetic information on different generations (Farrington et al. 2009). Research has examined other biological markers, such as resting heart rate (van de Weijer 2014), but no designs have directly investigated genetic transmission. Other research has assessed the role of biology indirectly, such as finding a lack of support for the hereditary perspective based on the observation that children of parents who stopped offending before the birth of the child were less likely to develop antisocial behavior problems. While this might point to some kind of direct transmission, it does not rule out genetic transmission: it could equally be that parents who desist before birth just happen to be less serious offenders (with fewer hereditary risk factors).

\section{Implications for Future Research}

The Cambridge-Somerville Youth Study produced decades of rigorous research on family risk factors for delinquent and criminal offending, but it was necessarily limited to two generations: parents (G1) and their sons (G2). 
Subsequent research using three or more generations has added considerably to the knowledge base on parental and intergenerational transmission. Yet, such research consists of only five major studies. As noted above, this literature is subject to several limitations. In addition to being small, it includes only one study of more than three generationsthe Transfive study (Bijleveld and Wijkman 2009). A three-and even a four-generation prospective study with self-report data or direct observation of early generations has not yet been accomplished, yet the Cambridge-Somerville Youth Study makes this a real possibility (Welsh and Zimmerman 2015).

\section{Transmission of Treatment Effects}

The Cambridge-Somerville Youth Study presents a unique opportunity to study the transmission of treatment effects from G2 men (both treatment and control) to their G3 offspring. Studying the transmission of treatment effects is a relatively new research agenda (see, e.g. Gifford et al. 2015 , in the context of school performance of children of drug treatment court participants). To our knowledge, this has not yet been attempted in the field of criminology or adolescent development more generally. The literature on treatment effects-positive, null, and iatrogenic-often focuses on short-term effects, but the importance of investigating long-term treatment effects has also been suggested (see, e.g., Sawyer et al. 2015; Weisz 2014). Studying transmission of treatment effects to future generations is a natural extension of this long-term perspective. Specifically, looking at transmission of treatment effects helps us to understand the full impact that a treatment can have-both for better and for worse (see McCord 2003; Zane et al. 2016). In the case of the Cambridge-Somerville Youth Study, determining whether the iatrogenic effects that were detected at age 45 are transmitted to future generations poses a troubling question: did the treatment have harmful effects extending even beyond the direct participants?

\section{Intergenerational Transmission of Offending}

The continued study of intergenerational transmission of offending requires more designs of three or more generations. The Cambridge-Somerville Youth Study presents an opportunity to investigate intergenerational transmission of offending with direct observation of the treatment group (G2), as indicated by Cabot's design and emphasis on keeping detailed records of the treatment group. Collecting data on G3 - the offspring of G2-represents an important contribution to this literature. As others have suggested in the context of intergenerational transmission of offending, "studies that focus on intergenerational transmission in fact only produce associations but do not provide an explanation for these, nor, by implication, do they give directions for intervention" (Bijleveld and Wijkman 2009, p. 144). Central to this research is continued investigation of the causal mechanisms underlying intergenerational transmission of offending. Detailed information collected through official and unofficial data of G2 during adolescence and later at age 45 presents a wealth of information to assist in the study of causal mechanisms. McCord always stressed that the causal complexity of criminal behavior could not be explained by any "one" thing, a lesson surely applicable to research on the intergenerational transmission of offending:

Sorting out heredity and environment is like trying to decide whether nature or nurture is responsible for the bloom of an orchid. Although the color of the orchid is determined to a large extent biologically, whether an orchid will bloom at all depends on whether it receives sufficient sun, warmth, and water. If there is plenty of water and warmth but variable sunshine, the amount of sunshine will contribute all the variance to predictions about the heartiness of different colors of orchids (McCord 2001, p. 224).

McCord further emphasized the importance of studying complex interactions among biological, developmental (family and peer), and community risk factors in order to understand intergenerational transmission of deviant behaviors: "integrated knowledge, crossing biological, sociological, and psychological components of development, would greatly increase the probability for understanding criminal behavior and perhaps for crime prevention" (McCord 2001, p. 230). As the end of this quote demonstrates, this is potentially more than just a theoretical question. As McCord (1999c, p. 177) suggested, "the transmission of violence between generations seems also to rest on concomitant circumstances that may, in fact, be altered to help end the continuity of violence from one generation to another."

\section{Conclusion}

Decades of research evidence make clear that family risk factors are importantly related to pro-social adolescent development, including future antisocial behavior and offending (Farrington et al. 2001). This includes increasingly more sophisticated approaches to understanding the complex nature of adolescent development and its lessons for promoting positive development through social interventions (see, e.g., Kramer-Kuhn and Farrell 2016; Lerner et al. 2001). While developmental prevention programs (e.g., Kurtines et al. 2008) and longitudinal research designs 
on developmental risk and protective factors (e.g., Buehler and Gerard 2013; Fleming et al. 2010) are becoming more widely used, there nonetheless remains a limited understanding of how offending is transmitted across generations. Research on intergenerational transmission of offending has just begun to address these important questions.

If the wealth of existing data on the Cambridge-Somerville Youth Study were supplemented with detailed information from subsequent generations - the children (G3) and possibly even grandchildren (G4) of the study participantsthis would offer another important source for investigating intergenerational transmission of offending. Of equal interest, the study's longitudinal-experimental design will allow us to investigate the potential for transmission of treatment effects-a novel project. The legacy of Richard Clarke Cabot's delinquency prevention experiment may turn out to be even greater than Joan McCord envisioned. We suspect that she would have been quite pleased with this.

Acknowledgments The authors thank the anonymous reviewer and the journal editor for their especially helpful comments.

Authors' Contribution BCW conceived of the study, participated in its design, and contributed to the writing of the manuscript. SNZ participated in the design of the study and took the lead role in writing the manuscript. GMZ contributed to the writing of the manuscript. All authors read and approved the final manuscript.

Funding The authors did not receive funding for this project.

\section{Compliance with Ethical Standards}

Conflict of interest The authors report no conflict of interests.

Ethical Approval This project was approved by the Institutional Review Board at Northeastern University.

Informed Consent No data identifiable to a person were collected by the authors.

\section{References}

Besemer, S. (2014). The impact of timing and frequency of parental criminal behaviour and risk factors. Psychology, Crime, and Law, 20, 78-99.

Besemer, S., \& Farrington, D. P. (2012). Intergenerational transmission of criminal behaviour: Conviction trajectories of fathers and their children. European Journal of Criminology, 9, 120-141.

Besemer, S., Farrington, D. P., \& Bijleveld, C. C. J. H. (2013). Official bias in intergenerational transmission of criminal behaviour. British Journal of Criminology, 53, 438-455.

Bijleveld, C. C. J. H., \& Farrington, D. P. (2009). Editorial: The importance of studies of intergenerational transmission of antisocial behavior. Criminal Behaviour and Mental Health, 19, 77-79.

Bijleveld, C. C. J. H., \& Wijkman, M. (2009). Intergenerational continuity in convictions: A five-generation study. Criminal Behaviour and Mental Health, 19, 142-155.

Bleys, D., Soenens, B., Boone, L., Claes, S., Vliegen, N., \& Luyten, P. (2016). The role of intergenerational similarity and parenting in adolescent self-criticism: An actor-partner interdependence model. Journal of Adolescence, 49, 68-76.

Buehler, C., \& Gerard, J. M. (2013). Cumulative family risk predicts increases in adjustment difficulties across early adolescence. Journal of Youth and Adolescence, 42, 905-920.

Cabot, R. C. (1931). Treatment in social case work and the need of criteria and of tests of its success or failure: Presidential address. In Proceedings of the national conference of social work (pp. 3-24).

Cabot, R. C. (1934). 1000 delinquent boys: First findings of the Harvard Law School's survey of crime. Survey, 70, 38-40.

Cabot, P. S. deQ. (1940). A long-term study of children: The Cambridge-Somerville Youth Study. Child Development, 11, 143-151.

Capaldi, D. M., Pears, K. C., Kerr, D. C. R., Owen, L. D., \& Kim, H. K. (2012). Growth in externalizing and internalizing problems in childhood: A prospective study of psychopathology across three generations. Child Development, 83, 1945-1959.

Capaldi, D. M., Pears, K. C., Patterson, G. R., \& Owen, L. D. (2003). Continuity of parenting practices across generations in an at-risk sample: A prospective comparison of direct and mediated associations. Journal of Abnormal Psychology, 31, 127-142.

Deković, M. (1999). Risk and protective factors in the development of problem behavior during adolescence. Journal of Youth and Adolescence, 28, 667-685.

DeLisi, M., Wright, J. P., Vaughn, M. G., \& Beaver, K. M. (2010). Nature and nurture by definition means both: A response to Males. Journal of Adolescent Research, 25, 24-30.

Deng, S., Lopez, V., Roosa, M. W., Ryu, E., Burrell, G. L., Tein, J. Y., et al. (2006). Family processes mediating the relationship of neighborhood disadvantage to early adolescent internalizing problems. The Journal of Early Adolescence, 26, 206-231.

Dong, B., \& Krohn, M. D. (2015). Exploring intergenerational discontinuity in problem behavior: Bad parents with good children. Youth Violence and Juvenile Justice, 13, 99-122.

Eckenrode, J., Campa, M., Luckey, D. W., Henderson, C. R., Cole, R., Kitzman, H., et al. (2010). Long-term effects of prenatal and infancy nurse home visitation on the life course of youths: 19-year follow-up of a randomized trial. Archives of Pediatrics and Adolescent Medicine, 164, 9-15.

Fan, Y., \& Chen, Q. (2012). Family functioning as a mediator between neighborhood conditions and children's health: Evidence from a national survey in the United States. Social Science and Medicine, 74, 1939-1947.

Farrington, D. P. (2006). Key longitudinal-experimental studies in criminology. Journal of Experimental Criminology, 2, 121-141.

Farrington, D. P. (2011). Families and crime. In J. Q. Wilson \& J. Petersilia (Eds.), Crime and public policy (pp. 130-157). New York: Oxford University Press.

Farrington, D. P. (2013). Longitudinal and experimental research in criminology. Crime and Justice: A Review of Research, 42, 453-527.

Farrington, D. P., Barnes, G., \& Lammbert, S. (1996). The concentration of offending in families. Legal and Criminological Psychology, 1, 47-63.

Farrington, D. P., Coid, J. W., \& Murray, J. (2009). Family factors in the intergenerational transmission of offending. Criminal Behaviour and Mental Health, 19, 109-124.

Farrington, D. P., Jolliffe, D., Loeber, R., Stouthamer-Loeber, M., \& Kalb, L. M. (2001). The concentration of offenders in families, and family criminality in the prediction of boys' delinquency. Journal of Adolescence, 24, 579-596.

Farrington, D. P., Piquero, A. R., \& Jennings, W. G. (2013). Offending from childhood to late middle age: Recent results from the Cambridge Study in Delinquent Development. New York: Springer. 
Farrington, D. P., Ttofi, M. M., Crago, R. V., \& Coid, J. W. (2015). Intergenerational similarities in risk factors for offending. Journal of Developmental and Life Course Criminology, 1, $48-62$.

Farrington, D. P., \& Welsh, B. C. (2006). A half century of randomized experiments on crime and justice. Crime and Justice: A Review of Research, 34, 55-132.

Fleming, C. B., Catalano, R. F., Haggerty, K. P., \& Abbott, R. D. (2010). Relationships between level and change in family, school, and peer factors during two periods of adolescence and problem behavior at age 19. Journal of Youth and Adolescence, 39, 670-682.

Forsetlund, L., Chalmers, I., \& Bjørndal, A. (2007). When was random allocation first used to generate comparison groups in experiments to assess the effect of social interventions? Economics of Innovation and New Technology, 16, 371-384.

Frisell, T., Lichenstein, P., \& Långström, N. (2011). Violent crime runs in families: A total population study of 12.5 million individuals. Psychological Medicine, 41, 97-105.

Galambos, N. L., Barker, E. T., \& Almeida, D. M. (2003). Parents do matter: Trajectories of change in externalizing and internalizing problems in early adolescence. Child Development, 74, 578-594.

Gifford, E. J., Sloan, F. A., Eldred, L. M., \& Evans, K. E. (2015). Intergenerational effects of parental substance-related convictions and adult drug treatment court participation on children's school performance. American Journal of Orthopsychiatry, 85, $452-468$.

Hammen, C., Brennan, P. A., \& Le Brocque, R. (2011). Youth depression and early childrearing: Stress generation and intergenerational transmission of depression. Journal of Consulting and Clinical Psychology, 79, 353-363.

Hope, T. (1995). Community crime prevention. In M. Tonry \& D. P. Farrington (Eds.), Building a safer society (pp. 21-89). Chicago: University of Chicago Press.

Johnson, K. A., \& Tyler, K. A. (2007). Adolescent sexual onset: An intergenerational analysis. Journal of Youth and Adolescence, 36, 939-949.

Junger, M., Greene, J., Schipper, R., Hesper, F., \& Estourgie, V. (2013). Parental criminality, family violence, and intergenerational transmission of crime within a birth cohort. European Journal on Criminal Policy and Research, 19, 1-17.

Kramer-Kuhn, A. M., \& Farrell, A. D. (2016). The promotive and protective effects of family factors in the context of peer and community risks for aggression. Journal of Youth and Adolescence, 45, 793-811.

Kurtines, W. M., Ferrer-Wreder, L., Berman, S. L., Lorente, C. C., Briones, E., Montgomery, M. J., et al. (2008). Promoting positive youth development: The Miami Youth Development Project (YDP). Journal of Adolescent Research, 23, 256-267.

Lerner, R. M., Lerner, J. V., De Stefanis, I., \& Apfel, A. (2001). Understanding developmental systems in adolescence: Implications for methodological strategies, data analytic approaches, and training. Journal of Adolescent Research, 16, 9-27.

Mahatmya, D., \& Lohman, B. J. (2012). Predictors and pathways to civic involvement in emerging adulthood: Neighborhood, family, and school influences. Journal of Youth and Adolescence, 41, $1168-1183$.

Males, M. (2009). Does the adolescent brain make risk taking inevitable? A skeptical appraisal. Journal of Adolescent Research, 24, 3-20.

McCord, J. (1978). A thirty-year follow-up of treatment effects. American Psychologist, 33, 284-289.

McCord, J. (1979). Some child-rearing antecedents of criminal behavior in adult men. Journal of Personality and Social Psychology, 37, 1477-1486.
McCord, J. (1980). Patterns of deviance. In S. B. Sells, et al. (Eds.), Human functioning in longitudinal perspective: Studies of normal and psychopathic populations (pp. 157-165). Baltimore, MD: Williams \& Wilkins.

McCord, J. (1983). A forty year perspective on effects of child abuse and neglect. Child Abuse and Neglect, 7, 265-270.

McCord, J. (1986). Instigation and insulation: How families affect antisocial aggression. In J. Block, D. Olweus, \& M. R. Yarrow (Eds.), Development of antisocial and prosocial behavior (pp. 343-357). New York: Academic.

McCord, J. (1988a). Parental aggressiveness and physical punishment in long-term perspective. In G. T. Hotaling, D. Finkelhor, J. T. Kirkpatrick, \& M. A. Straus (Eds.), Family abuse and its consequences: New directions in research (pp. 91-98). Thousand Oaks, CA: Sage.

McCord, J. (1988b). Alcoholism: Toward understanding genetic and social factors. Psychiatry, 51, 131-141.

McCord, J. (1990a). Crime in moral and social contexts. Criminology, $28,1-26$.

McCord, J. (1990b). Long-term perspectives on parental absence. In L. N. Robins \& M. Rutter (Eds.), Straight and devious pathways from childhood to adulthood (pp. 116-134). New York: Cambridge University Press.

McCord, J. (1991a). Family relationships, juvenile delinquency, and adult criminality. Criminology, 29, 397-417.

McCord, J. (1991b). The cycle of crime and socialization practices. Journal of Criminal Law and Criminology, 82, 211-228.

McCord, J. (1992). The Cambridge-Somerville Study: A pioneering longitudinal experimental study of delinquency prevention. In J. McCord \& R. E. Tremblay (Eds.), Preventing antisocial behavior: Interventions from birth through adolescence (pp. 196-206). New York: Guilford Press.

McCord, J. (1993a). Conduct disorder and antisocial behavior: Some thoughts about processes. Development and Psychopathology, 5, 321-329.

McCord, J. (1993b). Descriptions and predictions: Three problems for the future of criminological research. Journal of Research in Crime and Delinquency, 30, 412-425.

McCord, J. (1994a). Family socialization and antisocial behavior: Searching for causal relationships in longitudinal research. In E. G. M. Weitekamp \& H.-J. Kerner (Eds.), Cross-national longitudinal research on human development and criminal behavior (pp. 177-188). Netherlands: Kluwer.

McCord, J. (1994b). Aggression in two generations: Current perspectives. In L. R. Huesmann (Ed.), Aggressive behavior: Current perspectives (pp. 241-251). New York: Plenum.

McCord, J. (1999a). Alcoholism and crime across generations. Criminal Behaviour and Mental Health, 9, 107-117.

McCord, J. (1999b). Understanding childhood and subsequent crime. Aggressive Behavior, 25, 241-253.

McCord, J. (1999c). Intergenerational transmission of violence. In R. Gottesman (Ed.), Violence in America: An encyclopedia (pp. 174-177). New York: Scribner.

McCord, J. (2001). Forging criminals in the family. In S. White (Ed.), Handbook of youth and justice (pp. 223-235). New York: Kluwer.

McCord, J. (2003). Cures that harm: Unanticipated outcomes of crime prevention programs. Annals of the American Academy of Political and Social Science, 587, 16-30.

McCord, W., \& McCord, J. (1959). Origins of crime: A new evaluation of the Cambridge-Somerville Youth Study. New York: Columbia University Press.

Powers, E. (1949). An experiment in the prevention of delinquency. Annals of the American Academy of Political and Social Science, $261,77-88$ 
Powers, E., \& Witmer, H. L. (1951). An experiment in the prevention of delinquency: The Cambridge-Somerville Youth Study. New York: Columbia University Press.

Raine, A. (2002). Biosocial studies of antisocial and violent behavior in children and adults: A review. Journal of Abnormal Child Psychology, 30, 311-326.

Raine, A. (2008). From genes to brain to antisocial behavior. Current Directions in Psychological Science, 17, 323-328.

Raudino, A., Fergusson, D. M., Woodward, L. J., \& Horwood, L. J. (2013). The intergenerational transmission of conduct problems. Social Psychiatry and Psychiatric Epidemiology, 48, 465-476.

Sawyer, A. M., Borduin, C. M., \& Dopp, A. R. (2015). Long-term effects of prevention and treatment on youth antisocial behavior: A meta-analysis. Clinical Psychology Review, 42, 130-144.

Sayre-McCord, G. (Ed.). (2007). Crime and family: Selected essays of Joan McCord. Philadelphia, PA: Temple University Press.

Schofield, T. J., Conger, R. D., Conger, K. J., Martin, M. J., Brody, G., Simons, R., et al. (2012). Neighborhood disorder and children's antisocial behavior: The protective effect of family support among Mexican American and African American families. American Journal of Community Psychology, 50, 101-113.

Schweinhart, L. J., Montie, J., Zongping, X., Barnett, W. S., Belfield, C. R., \& Nores, M. (2005). Lifetime effects: The High/Scope Perry Preschool study through age 40. Ypsilanti, MI: High/ Scope Press.

Smith, M. J., \& Clarke, R. V. (2012). Situational crime prevention: Classifying techniques using "good enough" theory. In B. C. Welsh \& D. P. Farrington (Eds.), The Oxford handbook of crime prevention (pp. 291-315). New York: Oxford University Press.

Smith, C. A., \& Farrington, D. P. (2004). Continuities in antisocial behaviour and parenting across three generations. Journal of Child Psychology and Psychiatry, 45, 230-247.

Steinberg, L. (1987). Familial factors in delinquency: A developmental perspective. Journal of Adolescent Research, 2, 255-268.

Steinberg, L. (2001). We know some things: Parent-adolescent relationships in retrospect and prospect. Journal of Research on Adolescence, 11, 1-19.

Thornberry, T. P. (2005). Explaining multiple patterns of offending across the life course and across generations. Annals of the American Academy of Political and Social Science, 602, 156-195.

Thornberry, T. P. (2009). The apple doesn't fall far from the tree (or does it?): Intergenerational patterns of antisocial behavior. Criminology, 47, 297-325.

Thornberry, T. P., Freeman-Gallant, A., Lizotte, A. J., Krohn, M. D., \& Smith, C. A. (2003). Linked lives: The intergenerational transmission of antisocial behavior. Journal of Abnormal Child Psychology, 31, 171-184.

Thornberry, T. P., Freeman-Gallant, A., \& Lovegrove, P. J. (2009). Intergenerational linkages in antisocial behaviour. Criminal Behaviour and Mental Health, 19, 80-93.
Tremblay, R. E. (2005). Towards an epigenetic approach to experimental criminology. Journal of Experimental Criminology, 1, 397-415.

Tremblay, R. E., \& Craig, W. M. (1995). Developmental crime prevention. In M. Tonry \& D. P. Farrington (Eds.), Building a safer society (pp. 151-236). Chicago: University of Chicago Press.

van de Rakt, M., \& Nieuwbeerta, P. (2005). Criminal careers of adult Dutch offenders: The Children (Codebook and Documentation). Leiden: NSCR.

van de Rakt, M., Nieuwbeerta, P., \& DeGraaf, N. D. (2008). Like father, like son: The relationships between conviction trajectories of fathers and their sons and daughters. British Journal of Criminology, 48, 538-556.

van de Rakt, M., Ruiter, S., De Graaf, N. D., \& Nieuwbeerta, P. (2010). When does the apple fall from the tree? Static versus dynamic theories predicting intergenerational transmission of convictions. Journal of Quantitative Criminology, 26, 371-389.

van de Weijer, S. (2014). The intergenerational transmission of violent offending. Ph.D. dissertation. Amsterdam: NSCR.

van de Weijer, S., Bijleveld, C. C. J. H., \& Blokland, A. A. J. (2014). The intergenerational transmission of violent offending. Journal of Family Violence, 29, 109-118.

Vitaro, F., Brendgen, M., Giguère, C. E., \& Tremblay, R. E. (2013). Early prevention of life-course personal and property violence: A 19-year follow-up of the Montreal Longitudinal-Experimental Study (MLES). Journal of Experimental Criminology, 9, 411-427.

Weisburd, D., \& Petrosino, A. (2004). Experiments, criminology. In K. Kempf-Leonard (Ed.), Encyclopedia of social measurement (pp. 877-884). San Diego, CA: Academic.

Weisz, J. R. (2014). Short-term treatment as long-term prevention: Can early intervention produce legacy effects? American Journal of Psychiatry, 171, 600-602.

Welsh, B. C., \& Zimmerman, G. M. (2015). Who cares about a delinquency prevention experiment of Boston boys born in the 1920s and 1930s? The need for long-term follow-ups in criminology. Criminal Behaviour and Mental Health, 25, 331-337.

West, D. J., \& Farrington, D. P. (1977). The delinquent way of life. London: Heinemann.

Widom, C. S., Czaja, S. J., \& DuMont, K. A. (2015). Intergenerational transmission of child abuse and neglect: Real or detection bias? Science, 347, 1480-1485.

Williams, L., \& Godfrey, B. (2015). Intergenerational offending in Liverpool and the north-west of England, 1850-1914. History of the Family, 20, 189-203.

Zane, S. N., Welsh, B. C., \& Zimmerman, G. M. (2016). Examining the iatrogenic effects of the Cambridge-Somerville Youth Study: Existing explanations and new appraisals. British Journal of Criminology, 56, 141-160. 